\title{
ELECTROCHEMICAL MODIFICATION OF CITRAL
}

\author{
R.M.G. RAJAPAKSE, J.S.H.Q. PERERA and M.I.M. NAWAS \\ Department of Chemistry, University of Peradeniya, Peradeniya.
}

(Received:06 June 1995; accepted: 12 January 1996)

\begin{abstract}
The cyclic voltammogramme of citral in $0.1 \mathrm{~mol} \mathrm{dm}^{-3}$ of each of tetrabutylammoniumtetrafluoroborate and $\mathrm{HClO}_{4}$ in acetonitrile on a $\mathrm{Pt}$ disc electrode has a characteristic reduction peak centred at $-1.23 \mathrm{~V}$ with respect to the saturated calomel electrode at room temperature. The exhaustive electrolysis of the system at this peak potential for $30 \mathrm{~min}$ results in the conversion of citral to 3,7-dimethyloctanol in nearly quantitative yield.
\end{abstract}

Key words: Citral, cyclic voltammetry, electrolysis, potentiostatic conditions, 3,7-dimethyloctanol.

\section{INTRODUCTION}

Whilst the utilization of electrochemical techniques in the synthesis of simple organic compounds and organic polymers has a long history, recent work of Fry et $a l^{1.5}$ has resulted in the adaptation of these techniques for the synthesis of complicated organic compounds such as natural products. These techniques are simple, straightforward and economically favourable. One of their main features is that many variables such as potential, current, time, background electrolyte, composition of the electrolyte, electrode materials etc. can be controlled at will, which is of great importance and usefulness. For instance, possible redox reactions can readily be identified by a cyclic voltammogramme (cv) of the material in a suitable background electrolyte at a suitable scan rate. The bulk electrolysis under potentiostatic or galvanostatic conditions then enables one to. optimize the yield. Another advantage is that the mechanism of the reaction can be studied simultaneously by studying the scan rate dependence of peak current values. The technique is at its best use when the desired reaction is otherwise diffcult to accomplish. The modification of essential oils presents an example of this category. As the isoprenoid structure of terpenes present in most essential oils is labile to common reagents such as acids, alkali and redox agents, the chemical modification of essential oils is not always straightforward. On the other hand, selective conversion of these compounds can be affected by means of electrochemical methods. ${ }^{6}$ This publication is based on electrochemical modification of citral under potentiostatic conditions.

\section{METHODS AND MATERIALS}

Electrochemical studies of citral were performed in a one compartment cell consisting of a Ptdisc (surface area $=3.85 \times 10^{-5} \mathrm{~m}^{2}$ ) working electrode, an aqueous calomel reference electrode (SCE) and a Pt gauze auxilliary electrode using an 
electrochemical analyzer (Oxford Electrodes). The signals were recorded on an $\mathrm{X}-\mathrm{Y}$ chart recorder (YEW model 3022). The reference electrode was placed very close to the working electrode with the help of a Luggin capillary in order to minimize the IR drop through the solution and all potentials quoted are with reference to SCE. All experiments were carried out at room temperature. The electrolytes used were deoxygenated acetonitrile solutions containing $0.1 \mathrm{~mol} \mathrm{dm}^{-3}$ tetrabutylammoniumtetrafluoroborate (TBATFB). In some of the experiments varying amounts of $\mathrm{HClO}_{4}$ were also used in addition to TBATFB. In a typical experiment, the required amount of citral, usually in 1-10 millimolar concentration, was dissolved in the deoxygenated background electrolyte and its cv recorded. The solution was then subjected to constant potential electrolysis. The reaction was followed by running a thin layer chromatograph (TLC) at ten minute intervals. The products were separated from the background electrolyte by extracting the former into n-hexane or carbontetrachloride and evaporating the solvent. ${ }^{1} \mathrm{H}$ NMR, IR and Mass Spectroscopic techniques were adopted in the identification of the product.

\section{RESULTS}

Figure 1 depicts cvs of citral (i) on a Pt-disc electrode in a deoxygenated solution containing $0.1 \mathrm{~mol} \mathrm{dm}^{-3} \mathrm{TBATFB}$ at a scan rate of $500 \mathrm{mV} \mathrm{s}^{-1}$ upon the addition of various amounts of citral. The cathodic peak positioned at $-0.37 \mathrm{~V}$ (versus SCE) is greatly enhanced as the citral concentration is increased. It is, therefore, clear that some reduction process of citral is occuring at the electrode under these conditions. The addition of $\mathrm{HClO}_{4}$ into the electrolyte at constant citral concentration resulted in an enormous enhancement of this peak current and a considerable cathodic shift as shown in figure 2 . The electrolyte of the composition $5 \mathrm{mmol} \mathrm{dm}^{-3}$ citral in $0.1 \mathrm{~mol} \mathrm{dm}^{-3}$ of each of $\mathrm{HClO}_{4}$ and TBATFB in acetonitrile, when subjected to constant potential electrolysis at its cathodic peak value of $-0.85 \mathrm{~V}$ gave several different products as indicated by its TLC (silica gel stationary phase). The expansion of the cathodic limit of the cv resulted in the appearance of a new peak centred at $-1.23 \mathrm{~V}$ whose height increased proportionately with the increase of the citral concentration (figure 3). Constant potential electrolysis of the system at this peak potential for $30 \mathrm{~min}$ gave only one spot in its TLC whose $R_{\mathrm{f}}$ value is 0.45 (silica gel stationary phase and EtOAc eluant) which is much smaller than that of citral ( 0.66 with the same adsorbent and the same eluant) indicating that the electrolytic product is more polar than citral. The pure product is a pale brown liquid at room temperature and obtained in $97 \%$ yield. The ${ }^{1} \mathrm{H}-\mathrm{NMR}$ spectrum of the product consists of peaks at $\delta\left(\mathrm{CCl}_{4}\right)$, $1.1(9 \mathrm{H}, \mathrm{d}, \mathrm{J}=3 \mathrm{~Hz}), 1.6(10 \mathrm{H}, \mathrm{m}), 2.5\left(1 \mathrm{H}\right.$, broad singlet, $\mathrm{D}_{2} \mathrm{O}$ exchangeable $)$ and $3.3\left(2 \mathrm{H}, \mathrm{t}, \mathrm{J}=4 \mathrm{~Hz}, \mathrm{CH}_{2} \mathrm{O}\right.$ protons). The IR spectrum of citral shows bands centred at $1650(\mathrm{C}=\mathrm{C}), 1670(\mathrm{C}=\mathrm{O})$ and $2995(\mathrm{C}-\mathrm{H}$ of $\mathrm{CHO}) \mathrm{cm}^{-1}$ but the product shows no IR absorption in the regions corresponding to $\mathrm{C}=\mathrm{C}$ or $\mathrm{C}=\mathrm{O}$. However, the product shows a broad band in the region $3250-3550 \mathrm{~cm}^{-1}$ due to $\mathrm{O}-\mathrm{H}$ absorption. The $\mathrm{M}^{+}$peak in the mass spectrum appears at $\mathrm{m} / \mathrm{e} 158$. These data lead to the unambi-guous identification of the electrolytic product as 3,7-dimethyloctanol(2). 

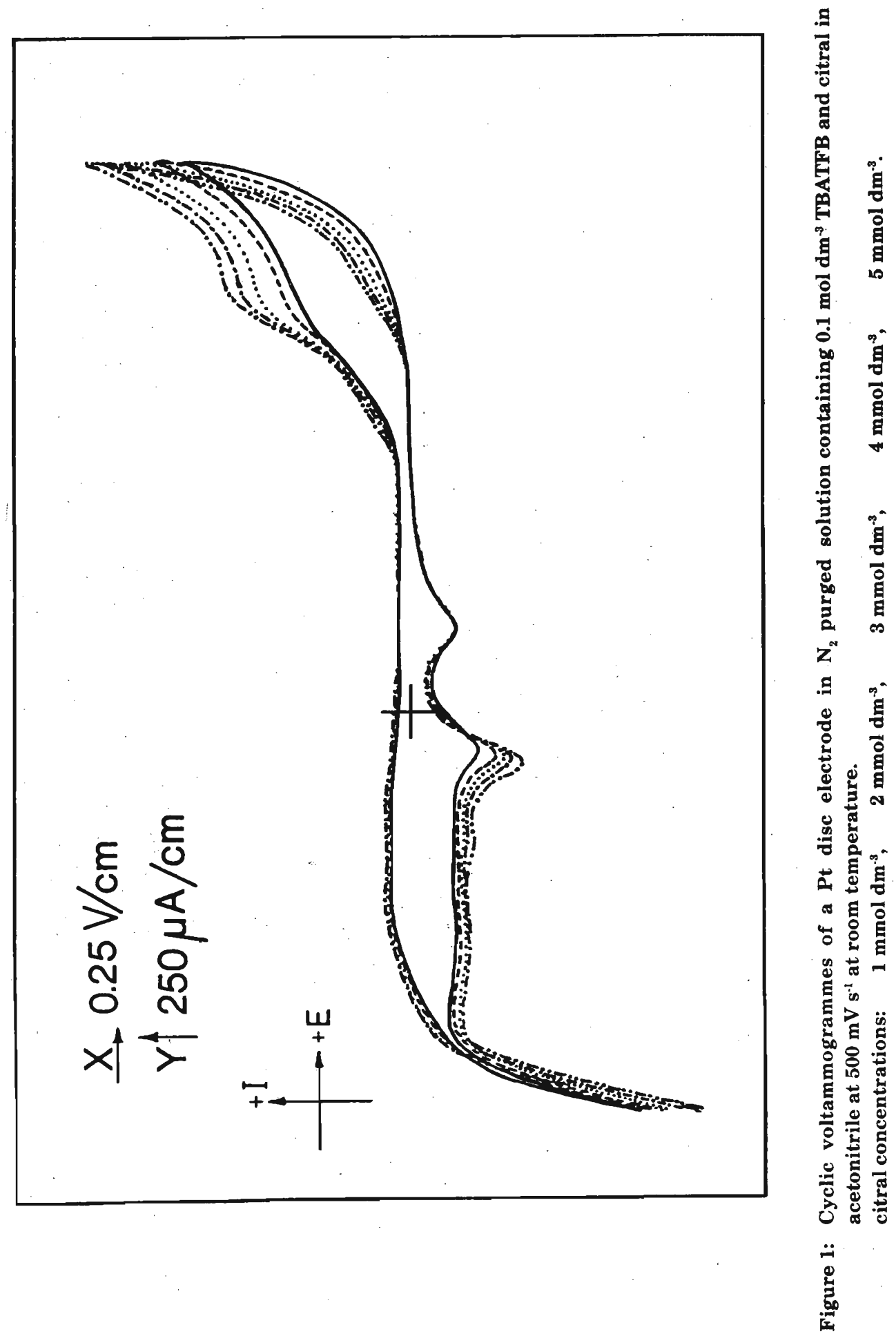


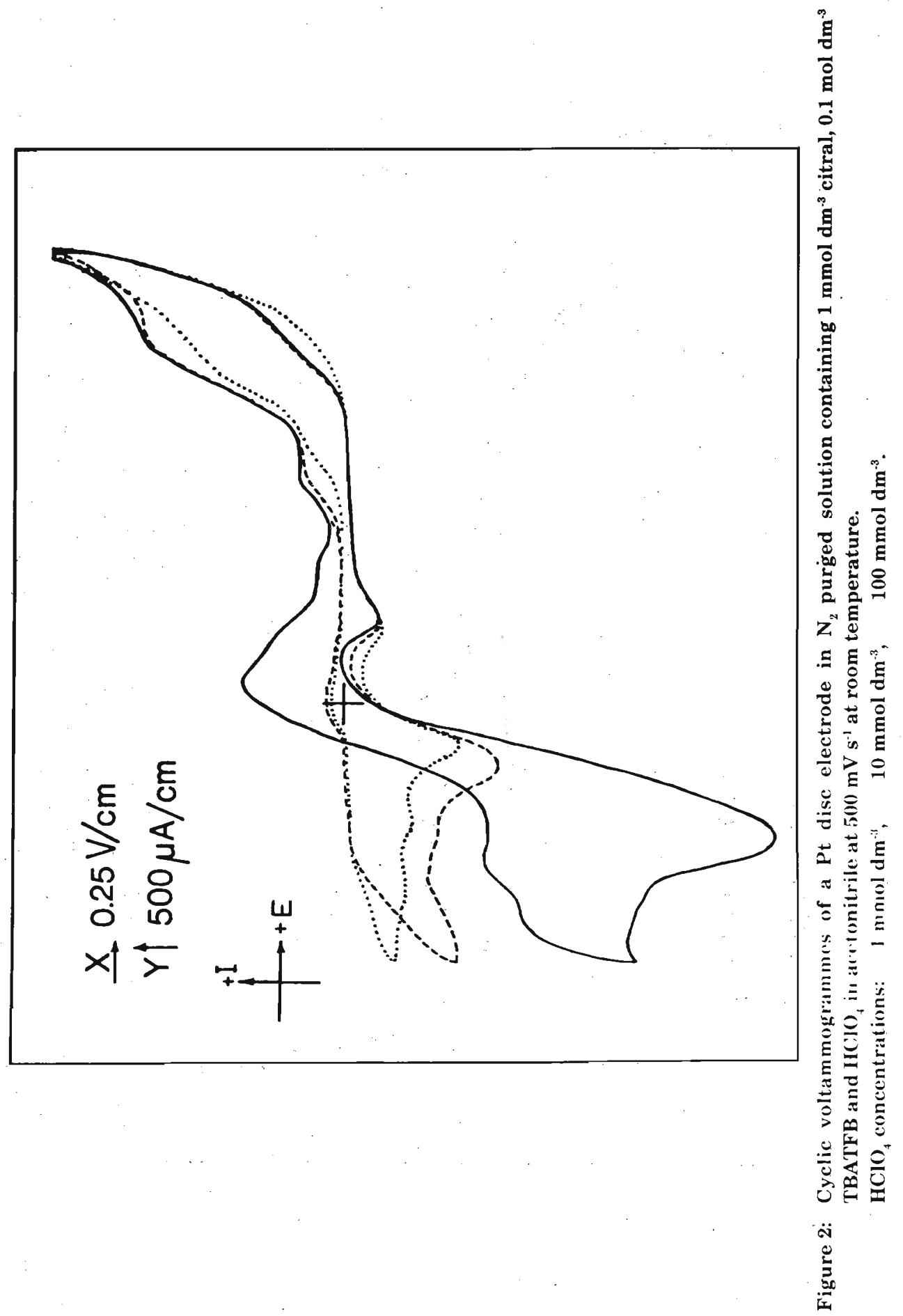




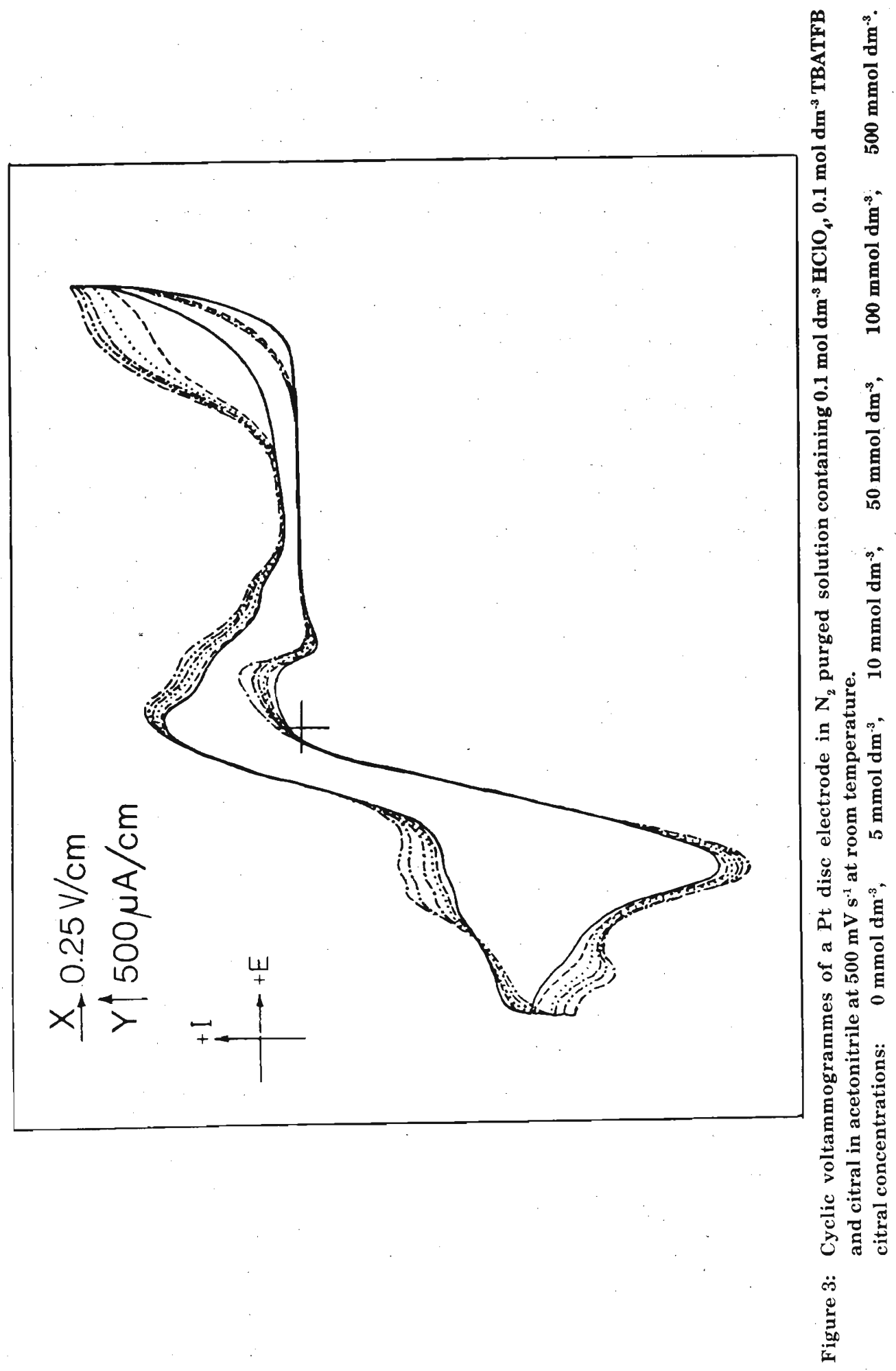




\section{DISCUSSION}

The increase in peak current at $-0.37 \mathrm{~V}$ upon the addition of citral into dry background electrolyte solution is not due to direct reduction of citral on the $\mathrm{Pt}$ surface. This is clearly understood from the simultaneous increase of Pt.oxidation wave which appears in the positive region of the $\mathrm{cv}$ upon the increase of citral concentration. The peak at $-0.37 \mathrm{~V}$. disappears when the potential is cycled between $-1.0 \mathrm{~V}$ and $0 \mathrm{~V}$. This peak is, therefore, due to the reduction of $\mathrm{PtO}$ which is formed in the forward scan. In the absence of any other electron acceptor, citral acts as a sacrificial electron acceptor for the oxidation of the Pt surface. Citral then undergoes reduction but at this potential it yields a mixture of products as revealed by its TLC. This idea is further supported by the drastic increase of peak current and a considerable cathodic shift of peak position observed upon the addition of $\mathrm{HClO}_{4}$. The reduction of $\mathrm{PtO}$ results in the generation of a clean $\mathrm{Pt}$ surface onto which citral is adsorbed. The direct reduction of citral on Pt surface then occurs at $-1.23 \mathrm{~V}$ resulting in the generation of 3,7-dimethyloctanol in nearly quantitative yields. A potential of $-1.23 \mathrm{~V}$ with respect to $\mathrm{SCE}$ is sufficient for the 6e-reduction of citral.

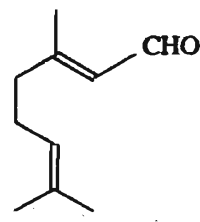

1 citral-a

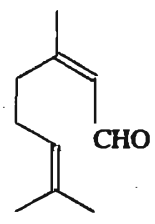

1

citral-b

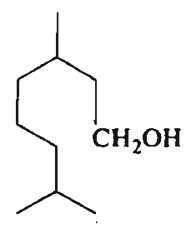

2
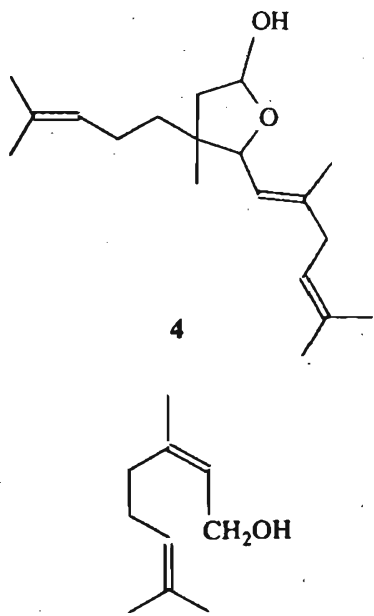
Previous workers have shown that the electrochemical modification of citral in acetate buffer containing $1 \mathrm{mmol} \mathrm{dm} \mathrm{m}^{-3}$ ethanol gave the following products under the stipulated conditions. ${ }^{6}$

(a) Constant potential electrolysis at $-1.25 \mathrm{~V}$ gave 3 .

(b) Constant potential electrolysis at $-1.23 \mathrm{~V}$ gave 4 .

(c) Constant current electrolysis at $3.5 \mathrm{~mA} \mathrm{~cm}^{-2}$ gave 5 .

Comparison of our results with those in the literature clearly shows that the choice of the background electrolyte is the key factor determining the reaction products. Another objective of this work was to utilize electrochemical techniques to effect economically useful conversions of essential oils such as the conversion of citral to geraniol (6). The latter is much more valuable than the former as it is widely used in the perfumery industry. Research is in progress in this line.

\section{References}

1. Fry A.J. (1993). Electrochemistry in organic synthesis, Aldrichimica Acta 26(1): 3-11.

2. Fry A.J. (1989). Cleavage of single bonds. In: Synthetic organic electrochemistry. 2nd ed. pp. 135-172. Wiley-Interscience, New York.

3. Fry A.J. (1989). Reduction of multiple bonds. In: Synthetic organic electrochemistry. 2nd ed. pp. 198-202. Wiley-Interscience, New York.

4. Fry A.J., Ankner H. \& Handa V.K. (1981). Electrochemical reduction of a,a' - dibromodibenzylsulphone, -sulphoxide and -monoxide. Tetrahedron Letters 22: 1791-1793.

5. Fry A.J., Ankner K. \& Handa V.K. (1981). Electrochemical reduction of 1,2-diphenylthiirene dioxide and monoxide. Journal of Chemical Society, Chemical Communication 3: 120-121.

6. Dharmasena P.A.S.H. (1983).Attempted electrochemical oxidation of citral, In: A study of electrochemical transformation of some constituents of Sri Lankan essential oils. M.Phil. Thesis, Peradeniya, 129-141. 